\title{
ASSESSING THE EFFECT OF TURNING VEHICLES AND PEDESTRIANS ON THE SAFETY OF AN URBAN ROAD SECTION (USING EXAMPLES FROM THE COMMONWEALTH OF INDEPENDENT STATES)
}

\author{
Denis KAPSKI ${ }^{1}$, Yauheni KOT ${ }^{1}$, Tetiana LUTSENKO², Oleksii PRASOLENKO², Andrii GALKIN²*, Oleksii LOBASHOV², \\ Sergii DULFAN ${ }^{2,3}$
}

\begin{abstract}
The article is devoted to an analysis of accidents involving pedestrians in traffic. An analysis of the statistical data of accidents involving pedestrians in the Republic of Belarus has been made. The main patterns and trends of accidents involving pedestrians are identified. A detailed analysis of the accident rate at pedestrian crossings and intersections was carried out, which made it possible to establish the most dangerous types of collisions during the interaction of transport and pedestrian flows. Experimental studies of collision situations were also carried out, which made it possible to establish the dependence of the violation rate on the composition of the right-handed traffic flow, on the type of traffic signal that regulates traffic on the right, as well as on the size of groups of pedestrians in front of cars.
\end{abstract}

Address

1 Belorussian National Technical University, Nezavisimosty Ave. 65, 220013 Minsk, Belorus

2 O. M. Beketov National University of Urban Economy, 17 M. Baganova St., 61002, Kharkiv, Ukraine

3 Director of Department for Infrastructure of Kharkiv City Council, 7, Constitution Sq., 7th floor, Kharkiv, 61001, Ukraine

* Corresponding author: galkin.tsl@gmail.com

Key words

- Road traffic,

- Pedestrian,

- Traffic conflicts,

- Crosswalk, Traffic light intersection,

- Road accidents,

- Risk.

\section{INTRODUCTION}

Pedestrians are the most numerous, unprepared, and unprotected category of road users. They are characterized by a huge dispersion of psychophysiological properties related to age, size, health, intelligence, education, level of knowledge of traffic, etc. (Földes, Csiszár, 2016). Therefore, much attention is being paid to studying the problems of road safety and pedestrians (Zegeer, Bushell, 2012). The behavior of pedestrians is often distinguished by seeming inconsistencies and unpredictability, although in fact everything is quite logical and predictable (WHO, 2013). It is logical from the point of view of a particular pedestrian, but predictably in the sense that illogical actions can always be expected from a pedestrian. In order for the driver to understand the logic of the pedestrian, he must know some of its features (Gorodokin, Almetova, Shepelev, 2017). For example, a pedestrian has more freedom in choosing directions that are not legally regulated and are not physically limited. In this case, not only the traffic situation, but also any other event, i.e., the appearance of a familiar, interesting sight, an unexpected sound, etc., can be a motive. Much depends on his age, well-being, etc. (Kapski, 2008). The person determines the distance to an object by the size of the silhouette of this object i.e., the smaller the silhouette, the greater the distance, and vice versa (Avineri, Shinar, Susilo, 2012). Having estimated the size of the silhouette of the object under study, for example, a car, a person compares these sizes with some standards stored in his memory and, in this way, "estimates" the distance. Obviously, such an estimate of the distance is approximate, and error is very likely. Moreover, the color of the vehicle affects this assessment, i.e., dark ones appear farther away, while bright ones, on the contrary, appear closer; the transparency of the air, the direction of the sun, the time of day, and the state of the pedestrian's health, experience, fatigue, etc., are also significant. It is easier for the driver here; he is constantly engaged in this work, he is healthy (getting a medical screening), sober, experienced, and has "working" standards. For a pedestrian, for obvious reasons, everything is much worse. Children are the most unpredictable in their behavior because they do not have enough experience of "everyday" road standards since they do not even immediately see the car as a whole, but in separate, most clearly distinguished fragments, for example, moldings, headlights, wheel caps, flicking windscreen wipers (Breen, 2002; Galkin et al., 2019). Older people, who devote a lot of their attention to not slipping or falling, also 
Tab. 1 Distribution of accidents with injured in the Republic of Belarus for 2003-2013(Bulbenkov, Lyvanskyi, Poludnia, 2011)

\begin{tabular}{|l|c|c|c|c|c|c|c|c|c|c|c|}
\hline \multicolumn{10}{|c|}{1 vehicle and pedestrian / Total } \\
\hline Years & 2003 & 2004 & 2005 & 2006 & 2007 & 2008 & 2009 & 2010 & 2011 & 2012 & 2013 \\
\hline Accident & $3371 /$ & $3361 /$ & $3370 /$ & $3513 /$ & $3103 /$ & $2872 /$ & $2684 /$ & $2517 /$ & $2361 /$ & $2010 /$ & $1834 /$ \\
& 7194 & 7218 & 7717 & 8283 & 7501 & 7238 & 6739 & 6363 & 5897 & 5187 & 4730 \\
\hline \multirow{2}{*}{ Died, people } & $760 /$ & $739 /$ & $729 /$ & $749 /$ & $606 /$ & $596 /$ & $520 /$ & $485 /$ & $478 /$ & $396 /$ & $371 /$ \\
& 1764 & 1688 & 1673 & 1726 & 1518 & 1564 & 1322 & 1190 & 1200 & 1039 & 894 \\
\hline \multirow{2}{*}{ Injured, people } & $2809 /$ & $2831 /$ & $2855 /$ & $2945 /$ & $2671 /$ & $2431 /$ & $2300 /$ & $2178 /$ & $2021 /$ & $1710 /$ & $1537 /$ \\
& 7361 & 7522 & 8047 & 8832 & 7990 & 7576 & 7198 & 6832 & 6334 & 5569 & 5033 \\
\hline
\end{tabular}

have problems in traffic because the road standards have already begun to be erased from memory (Vrubel, Kapskyi, 2013; Schlosser, et. al., 2017). However, these are not all the significant factors; it is necessary to determine the speed of a moving car, which is estimated by the speed of change of its silhouette. If the silhouette increases rapidly, the speed is high; if slow, it means the speed is low (Galkin, et. al., 2018). Other standards should already be extracted from the memory, i.e., changes in the size of the silhouettes in order to compare them with the subject; then the speed can be estimated (Zeedyk, Kelly, 2003). In this case, the influence of the color of the vehicle, the transparency of the air, the status of memory, etc., has an even greater importance than when determining the distance. In addition, it must be borne in mind that at the same speed, the change in the size of the silhouettes at a small distance occurs much faster than in a long one. As a result, an error in determin- ing the speed, as well as in determining the distance, is very likely. And an error while determining the distance to an approaching car and its speed is more likely than its absence (Ekman, 1997). In other words, if an untrained person determines this distance and speed 10 times, he is guaranteed to make a significant mistake in more than five cases. The main issue is: can a driver in such situations rely only on the pedestrian or not? The answers are unequivocal. In terms of road preparation, the pedestrian is significantly inferior to the driver; this should be taken for granted and taken into account in the process of driving. In this regard, an accident analysis with pedestrians should be carried out in order to know the patterns and causes of accidents and to take adequate measures to eliminate them (Traffic Safety Facts, 2004).

An analysis of the statistical information contained in the official statistical bulletins of the Ministry of Internal Affairs of the Republic

Tab. 2 Distribution in the Republic of Belarus of road accident participants with victims and the victims themselves by category for 2003-2013 (Bulbenkov, Lyvanskyi, Melchenko, 2012)

\begin{tabular}{|c|c|c|c|c|c|c|c|c|c|c|c|}
\hline \multirow[t]{2}{*}{$\begin{array}{l}\text { Participant } \\
\text { categories }\end{array}$} & \multicolumn{11}{|c|}{$\begin{array}{c}\text { Participated in accident, people } \\
\text { Died people } \\
\text { Injured, people }\end{array}$} \\
\hline & 2003 & 2004 & 2005 & 2006 & 2007 & 2008 & 2009 & 2010 & 2011 & 2012 & 2013 \\
\hline \multirow{3}{*}{ Drivers } & 8826 & 8932 & 9648 & 10474 & 9477 & 9270 & 8796 & 8421 & 7696 & 6881 & 6400 \\
\hline & 440 & 397 & 413 & 437 & 398 & 430 & 369 & 329 & 315 & 304 & 247 \\
\hline & 1796 & 1879 & 2105 & 2400 & 2181 & 2171 & 2052 & 1999 & 1828 & 1605 & 1496 \\
\hline \multirow{3}{*}{ Pedestrians } & 3524 & 3508 & 3529 & 3647 & 3236 & 3011 & 2806 & 2638 & 2455 & 2095 & 1901 \\
\hline & 756 & 725 & 720 & 745 & 601 & 596 & 518 & 483 & 474 & 396 & 371 \\
\hline & 2757 & 2773 & 2803 & 2897 & 2631 & 2411 & 2280 & 2147 & 1978 & 1695 & 1527 \\
\hline \multirow{3}{*}{ Passengers } & 2712 & 2742 & 2995 & 3376 & 3052 & 2984 & 2785 & 2577 & 2471 & 2239 & 1898 \\
\hline & 367 & 393 & 374 & 358 & 365 & 391 & 302 & 256 & 287 & 241 & 194 \\
\hline & 2302 & 2308 & 2591 & 2975 & 2649 & 2560 & 2448 & 2286 & 2162 & 1989 & 1691 \\
\hline \multirow{3}{*}{ Cyclists } & 638 & 624 & 644 & 671 & 612 & 512 & 484 & 468 & 440 & 336 & 355 \\
\hline & 184 & 149 & 152 & 173 & 138 & 127 & 119 & 112 & 115 & 85 & 71 \\
\hline & 450 & 468 & 488 & 493 & 466 & 382 & 358 & 350 & 323 & 249 & 281 \\
\hline \multirow{3}{*}{ Carters } & 87 & 114 & 74 & 74 & 74 & 60 & 55 & 51 & 45 & 44 & 32 \\
\hline & 17 & 19 & 12 & 12 & 11 & 12 & 7 & 5 & 8 & 10 & 4 \\
\hline & 48 & 73 & 44 & 47 & 45 & 33 & 39 & 33 & 25 & 22 & 19 \\
\hline \multirow{3}{*}{ Others } & 8 & 27 & 25 & 26 & 23 & 27 & 30 & 25 & 20 & 12 & 26 \\
\hline & 0 & 5 & 2 & 1 & 5 & 8 & 7 & 5 & 1 & 3 & 7 \\
\hline & 8 & 21 & 16 & 20 & 18 & 19 & 21 & 17 & 18 & 9 & 19 \\
\hline \multirow{3}{*}{ Total } & 15795 & 15947 & 16915 & 18268 & 16474 & 15864 & 14956 & 14180 & 13127 & 11607 & 10612 \\
\hline & 1764 & 1688 & 1673 & 1726 & 1518 & 1564 & 1322 & 1190 & 1200 & 1039 & 894 \\
\hline & 7361 & 7522 & 8047 & 8832 & 7990 & 7576 & 7198 & 6832 & 6334 & 5569 & 5033 \\
\hline
\end{tabular}




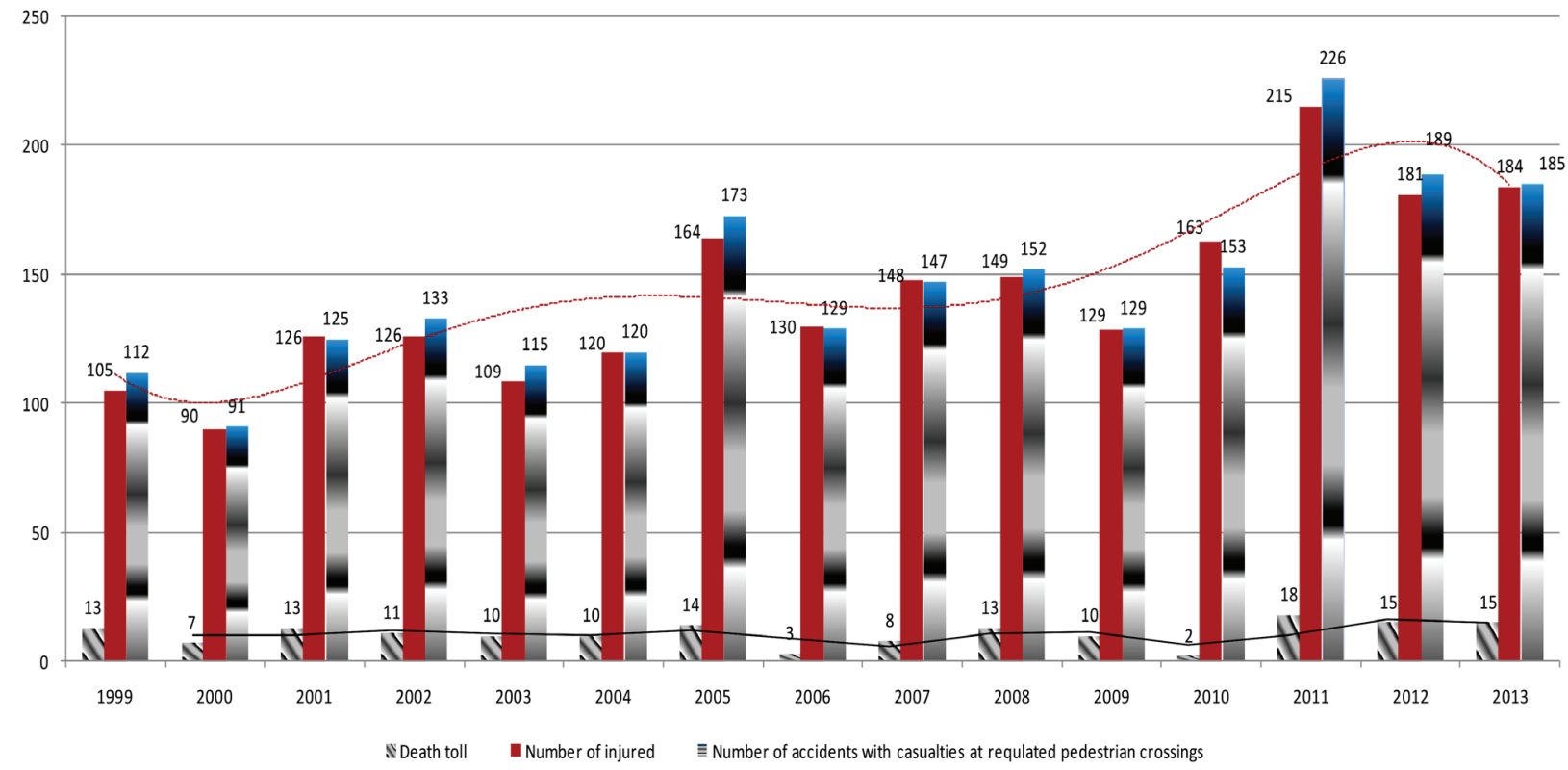

Fig. 1 Distribution of road accidents with victims and the victims themselves at regulated pedestrian crossings of the Republic of Belarus for 2003-2013 (Azemsha, et al., 2015)

of Belarus (Bulbenkov, Lyvanskyi, Poludnia, 2011; Bulbenkov, Lyvanskyi, Melchenko, 2012; Azemsha, et al., 2015), established that the accident rate involving pedestrians is $38-45 \%$ of all accidents with injuries (Tab. 1). Moreover, as can be seen from Table 2, about $40 \%$ of those killed in accidents are pedestrians.

It should be noted that more than $30 \%$ of the injured in traffic accidents are pedestrians out of the total number of road users involved in an accident (see Tab. 2).
Figure 1 shows the distribution of accidents with injured people and the number of the injured themselves at regulated pedestrian crossings in the Republic of Belarus in the time period studied (10 years). It can be seen that a small burst was observed in 2011. This increase in accidents is quite possibly related to the then economic crisis, which may have significantly affected the welfare of pedestrians and caused their distraction from the traffic process to more pressing problems.

Tab. 3 Distribution of road accidents with injured people due to violations of traffic regulations by pedestrians in the Republic of Belarus for 2003-2013 (Bulbenkov, Lyvanskyi, Melchenko, 2012)

\begin{tabular}{|c|c|c|c|c|c|c|c|c|c|c|c|}
\hline \multirow[t]{2}{*}{ Indicator } & \multicolumn{11}{|c|}{$\begin{array}{l}\text { Accident } \\
\text { Died } \\
\text { Injured }\end{array}$} \\
\hline & 2003 & 2004 & 2005 & 2006 & 2007 & 2008 & 2009 & 2010 & 2011 & 2012 & 2013 \\
\hline $\begin{array}{l}\text { Crossing over a } \\
\text { carriageway in an } \\
\text { unsuitable place }\end{array}$ & $\begin{array}{c}1228 \\
-\end{array}$ & $\begin{array}{c}1102 \\
-\end{array}$ & $\begin{array}{l}1055 \\
216 \\
872\end{array}$ & $\begin{array}{l}1154 \\
230 \\
958\end{array}$ & $\begin{array}{l}907 \\
198 \\
728\end{array}$ & $\begin{array}{l}710 \\
153 \\
573\end{array}$ & $\begin{array}{l}682 \\
132 \\
559\end{array}$ & $\begin{array}{l}605 \\
119 \\
505\end{array}$ & $\begin{array}{l}507 \\
123 \\
403\end{array}$ & $\begin{array}{l}442 \\
102 \\
347\end{array}$ & $\begin{array}{c}369 \\
94 \\
283\end{array}$ \\
\hline $\begin{array}{l}\text { The drunken state of the } \\
\text { pedestrian }\end{array}$ & $\begin{array}{c}575 \\
-\end{array}$ & $\begin{array}{c}650 \\
-\end{array}$ & $\begin{array}{l}533 \\
101 \\
453\end{array}$ & $\begin{array}{l}547 \\
105 \\
459\end{array}$ & $\begin{array}{c}498 \\
87 \\
436\end{array}$ & $\begin{array}{c}400 \\
74 \\
343\end{array}$ & $\begin{array}{c}411 \\
83 \\
335\end{array}$ & $\begin{array}{c}369 \\
66 \\
314\end{array}$ & $\begin{array}{c}314 \\
76 \\
247\end{array}$ & $\begin{array}{c}298 \\
64 \\
245\end{array}$ & $\begin{array}{c}289 \\
71 \\
226\end{array}$ \\
\hline $\begin{array}{l}\text { Unexpected exit } \\
\text { from the vehicle, } \\
\text { constructions, trees, etc. }\end{array}$ & $\begin{array}{c}298 \\
-\end{array}$ & $\begin{array}{c}296 \\
-\end{array}$ & $\begin{array}{c}217 \\
37 \\
183 \\
\end{array}$ & $\begin{array}{c}217 \\
39 \\
181 \\
\end{array}$ & $\begin{array}{c}213 \\
45 \\
176 \\
\end{array}$ & $\begin{array}{c}202 \\
43 \\
166 \\
\end{array}$ & $\begin{array}{c}156 \\
22 \\
135 \\
\end{array}$ & $\begin{array}{c}167 \\
34 \\
134 \\
\end{array}$ & $\begin{array}{c}146 \\
31 \\
124 \\
\end{array}$ & $\begin{array}{c}104 \\
14 \\
92 \\
\end{array}$ & $\begin{array}{l}77 \\
14 \\
63 \\
\end{array}$ \\
\hline $\begin{array}{l}\text { Disobeying traffic } \\
\text { control signals }\end{array}$ & $\begin{array}{l}71 \\
-\end{array}$ & $\begin{array}{l}88 \\
-\end{array}$ & $\begin{array}{c}135 \\
11 \\
126 \\
\end{array}$ & $\begin{array}{c}79 \\
5 \\
77 \\
\end{array}$ & $\begin{array}{c}77 \\
4 \\
79 \\
\end{array}$ & $\begin{array}{l}86 \\
11 \\
80 \\
\end{array}$ & $\begin{array}{c}73 \\
7 \\
70 \\
\end{array}$ & $\begin{array}{c}75 \\
6 \\
70 \\
\end{array}$ & $\begin{array}{l}83 \\
10 \\
75\end{array}$ & $\begin{array}{l}81 \\
12 \\
70\end{array}$ & $\begin{array}{c}63 \\
8 \\
58 \\
\end{array}$ \\
\hline Games on the roadway & $\begin{array}{c}120 \\
-\end{array}$ & $\begin{array}{c}262 \\
-\end{array}$ & $\begin{array}{l}239 \\
106 \\
150 \\
\end{array}$ & $\begin{array}{l}235 \\
117 \\
132 \\
\end{array}$ & $\begin{array}{c}163 \\
64 \\
106 \\
\end{array}$ & $\begin{array}{c}156 \\
70 \\
95 \\
\end{array}$ & $\begin{array}{c}156 \\
71 \\
93 \\
\end{array}$ & $\begin{array}{c}165 \\
72 \\
97 \\
\end{array}$ & $\begin{array}{c}178 \\
100 \\
84 \\
\end{array}$ & $\begin{array}{l}70 \\
33 \\
38 \\
\end{array}$ & $\begin{array}{l}57 \\
27 \\
33 \\
\end{array}$ \\
\hline $\begin{array}{l}\text { A pedestrian } \\
\text { under } 7 \text { years old } \\
\text { unaccompanied by an } \\
\text { adult }\end{array}$ & $\begin{array}{c}26 \\
-\end{array}$ & $\begin{array}{l}36 \\
-\end{array}$ & $\begin{array}{c}37 \\
6 \\
35\end{array}$ & $\begin{array}{c}26 \\
1 \\
26\end{array}$ & $\begin{array}{c}19 \\
1 \\
18\end{array}$ & $\begin{array}{c}17 \\
1 \\
16\end{array}$ & $\begin{array}{c}10 \\
0 \\
10\end{array}$ & $\begin{array}{c}14 \\
3 \\
11\end{array}$ & $\begin{array}{c}16 \\
1 \\
15\end{array}$ & $\begin{array}{l}9 \\
1 \\
8\end{array}$ & $\begin{array}{l}8 \\
0 \\
8\end{array}$ \\
\hline $\begin{array}{l}\text { Other traffic violations } \\
\text { by pedestrians }\end{array}$ & $\begin{array}{c}226 \\
-\end{array}$ & $\begin{array}{c}222 \\
-\end{array}$ & $\begin{array}{c}330 \\
90 \\
146\end{array}$ & $\begin{array}{l}236 \\
105 \\
135\end{array}$ & $\begin{array}{l}386 \\
172 \\
228\end{array}$ & $\begin{array}{l}350 \\
164 \\
195\end{array}$ & $\begin{array}{l}336 \\
143 \\
203 \\
\end{array}$ & $\begin{array}{l}342 \\
155 \\
192 \\
\end{array}$ & $\begin{array}{l}306 \\
151 \\
165\end{array}$ & $\begin{array}{l}243 \\
117 \\
131 \\
\end{array}$ & $\begin{array}{c}177 \\
84 \\
97\end{array}$ \\
\hline
\end{tabular}


The problem of the human factor in ensuring road safety, especially in times of limited visibility, is related to the mechanisms of perception and the processing of information by the driver in accordance with the traffic situation. The speed of information processing by the driver is influenced by many factors: his functional and emotional state, the extent of any illumination, the road conditions, the presence of obstacles on a certain section of the road, the presence and condition of road markings, road signs, road equipment, traffic lights, etc. (Prasolenko, et. al., 2019). Thus, the time of the reaction and the number of conflict situations will directly depend on the traffic infrastructure and the organization of the traffic, intersections, and roads. Investigating conflict situations and violations in different sections will allow for the assessment of the influence of traffic factors on the number of traffic accidents in order to reduce their number. The results of this research points to a lack of overall and detailed considerations of vehicle-vehicle, vehicle-pedestrian, and vehicle-infrastructure behaviour along an entire journey in urban areas (Vakulenko, et. al., 2019). The purpose of the research is to assess the safety of an urban road section when considering accidents involving turning vehicles and pedestrians.

\section{APPROACHES AND PRINCIPLES OF THE RESEARCH IN DETAIL}

Accidents involving pedestrians have also been investigated by many authors (Draskóczy, Hydén, 1995). The results of an analysis of accidents involving transport-pedestrian conflicts at regulated intersections are presented in (Kot, 1991). Up to $90 \%$ of accidents with pedestrians occur with the participation of the vehicle in the direct (transit) direction, which is explained by the high speed of the traffic flow. Accidents involving turning vehicles and pedestrians account for about $10 \%$, which is explained by the relatively low speed of the turning flows. In (Lenard, Badea-Romero, Danton, 2014), traffic flows interacting with pedestrians crossing the carriageway from left to right and from right to left as a car was moving were also analyzed (Schlosser, et. al., 2016). Conflict interactions between pedestrians and left-handed transverse flows ware studied in (Lord, Smiley, Haroun, 1998), in which the degree of danger of a collision between pedestrians and wheeled vehicles was investigated.

In (Ewing, 1996), the results of the forecasting of accidents in a transport - pedestrian conflict are presented using the method of conflict situations. The method is based on the existence of a relationship between the number of conflict situations and accidents and is one of the most modern and rapidly developing methods for predicting accidents (Archer, 2001). By counting the number of conflict situations at a given object in a relatively short time, it is possible to determine with sufficient accuracy not only the number of expected accidents, but also the main causes of the accident. It is established that for 10,000 conflict situations at low speeds $(\mathrm{V} \leq 30 \mathrm{~km} / \mathrm{h})$ there are from 3 to 25 accidents, and at high speeds ( $\mathrm{V} \geq 30 \mathrm{~km} / \mathrm{h}$ ) - from 25 to 55 accidents. Traffic light intersections and junctions are characterized by higher values for the conversion factor of conflict situations in an accident than for unregulated sections. In (Kapski, Pegin, Korchagin, 2015), a method was proposed for classifying intersections by hazard for pedestrians, based on 5 factors: the number of accidents with pedestrians, relative pedestrian accidents, the ratio of individual age groups of pedestrians, the level of disobedience of signals, and the number of traffic-pedestrian conflicts. Pedestrian hazard indicator $F$ is determined by the formula:

$$
\Phi=\sum_{1}^{n} \frac{W F_{i} H v_{i}}{\sum_{1}^{n} W F_{i}}
$$

where

$W F_{i}$ - the weight factor of the private indicator $i$;

$H v_{i}$ - the hazard (risk) level for the private indicator $i$;

$\sum_{i}^{n} W F_{i}$ tion studied;

$n$ - the number of risk factors (indicators), $n=5$.

The relative pedestrian accident rate for each intersection studied was normalized for its correlation with other intersections and was determined as the ratio of the average annual number of accidents involving pedestrians at the studied intersection to the total volume of traffic and pedestrian traffic. When determining the volume of traffic, the total mileage of the vehicle at the intersection and the total paths that pedestrians walk along all the pedestrian crossings of the intersection were taken into account. As an additional factor, the share of vehicles performing corner maneuvers was taken into account.

As a result, the relative pedestrian accident rate was proposed to be determined by the formula:

$$
A R=\frac{n_{a 3} \cdot 10^{7}}{P \cdot P_{n}} \Delta_{\text {пов }}
$$

where

$n_{a 3}$ - the number of accidents involving pedestrians over 3 years old (7 a.m.-6 p.m.);

$P$ - vehicle run for the period 7a.m. - 6p.m., auto-km;

$P_{n}-$ the pedestrian walking route for the time of 7 a.m. -6 p.m., people-km;

$\Delta_{n о в}-$ rate of the turning vehicles at the intersection.

The relative pedestrian-transport conflict was defined as the proportion of pedestrians participating in the conflict with a vehicle (mainly a turning one).

To determine some of the accident parameters, a focal analysis was carried out. It contains a variety of topographies and consists of applying and studying all the available information about accidents on a large-scale diagram of the site (the outbreak). In the outbreak itself, in this case, at a regulated intersection, accidents are grouped into conflict zones located in certain parts of the intersection. This is because the accident rate depends, among other things, on the speed of the traffic flow and the mutual visibility of the participants. Since the parameters in the "transport - pedestrian" conflict in different parts of a pedestrian crossing differ significantly, their accident rate is not the same. According to the research, the designation scheme, index numbers, and names are shown in Fig. 2.

One of the approaches to the intersection is assigned number 1, while the remaining approaches are assigned numbers 2,3 , and 4 clockwise. Each of the traffic flows is assigned an index, the first digit
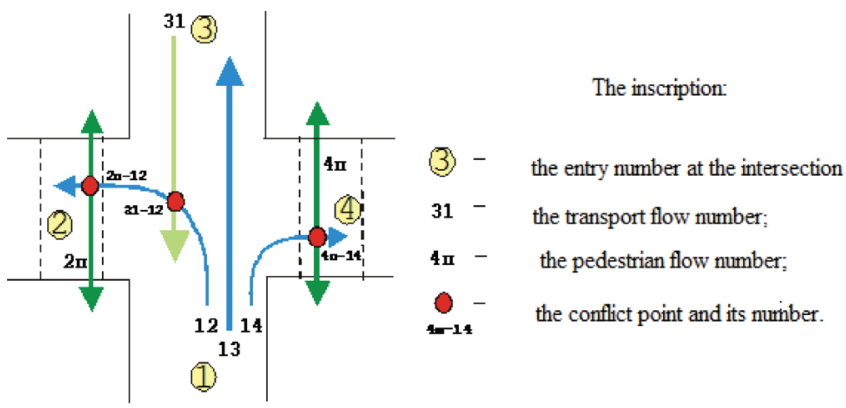

Fig. 2 Designation scheme of traffic and pedestrian flows and conflict points at an intersection 
of which indicates the number of the approach by which the vehicles of this stream arrived at the intersection (entrance); the second is the number of the approach by which they departed from the intersection (exit). For example, a left-turning flow arriving from input 1 has an index of 12; a forward direction flow (hereinafter referred to as a transit flow) has an index of 13; and a right-direction flow has an index of 14. In accordance with these approaches, the studies below were performed.

\section{EXPERIMENTAL RESEARCH AND RESULTS}

The statistical information on the accident rate in the conflict was collected for the pedestrian transport in four cities of the Republic of Belarus, i.e., Minsk, Vitebsk, Hrodna, Lida, and two other cities - St. Petersburg, Russia, and Almaty, Kazakhstan. These cities were selected in such a way as to detect possible differences depending on the size of the city, i.e., from St. Petersburg, where more than 6 million people live, to Lida, where about 100,000 people live. It should be noted right away that there were no fundamental differences in the accident characteristics depending on the size of the city for the samples studied.

Tab.3 shows some accident indicators in "transport-pedestrian" conflicts. About $7-17 \%$ of all accidents involving pedestrians occur at traffic light intersections. Moreover, the accident rate in "the turn transport - pedestrian" conflict makes up from $5 \%$ to $20 \%$ of the accident rate with pedestrians at traffic light intersections or from 0.6 to $2 \%$ of the total accident rate with the participation of pedestrians.

The severity of the consequences of accidents in "the turning vehicle - pedestrian" conflict is significantly lower than the average severity of accidents involving pedestrians, i.e., 3 deaths per 100 injured (in general, this ratio is 100: 27). It should be noted that in the current accounting system, accidents involving pedestrians that did not affect their health are equated to accidents without injuries and are not included in the state statistical reporting, i.e., they have the status of "non-reporting". It is possible to obtain information about such accidents, as a rule, if there are systems for their automated metering and analysis, which are not used in all the cities. It is necessary to keep records of "non-reporting" accidents, which do not contradict and even correspond to the current government approaches in the Republic of Belarus for the accounting and analysis of indicators and accident indicators.

Most of the accidents investigated (81\%) were caused by drivers who, in violation of the traffic rules, did not let pedestrians walk across the pedestrian crossing. However, about $19 \%$ of the accidents were caused by pedestrians; basically, they occurred in the passage of the carriageway outside the pedestrian crossing (next to it) and the unexpected exit to the carriageway when the driver does not have the technical ability to stop and avoid a collision. The percentage of children under 14 years old is about $20 \%$ from the total number of injured, which is close to the average value for accidents involving pedestrians. The accident losses in the conflicts investigated that were calculated by the method (Vrubel, Kapski, Kot, 2006), are approximately $0.1-0.3 \%$ from the total accidents involving pedestrians. Therefore, the accident rate in a conflict involving pedestrians at traffic light intersections occupies a modest place in the general accident rate with the participation of pedestrians. Nevertheless, it does exist; it leads to socio-economic losses and must be taken into account

Tab. 3 Average annual accident rates involving pedestrians

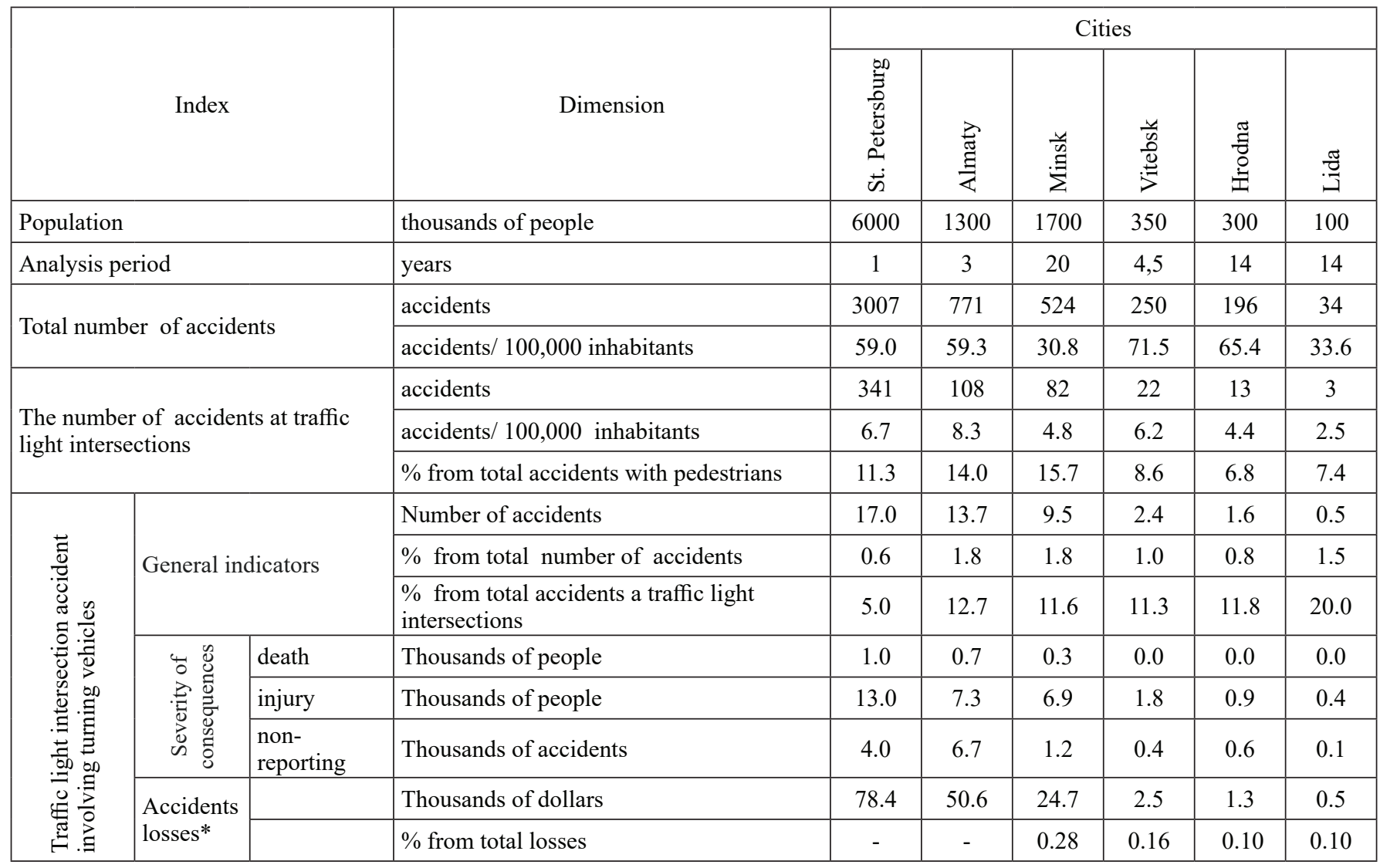

Notes: * - data of the cost of 1 accident - according to work [4]. 


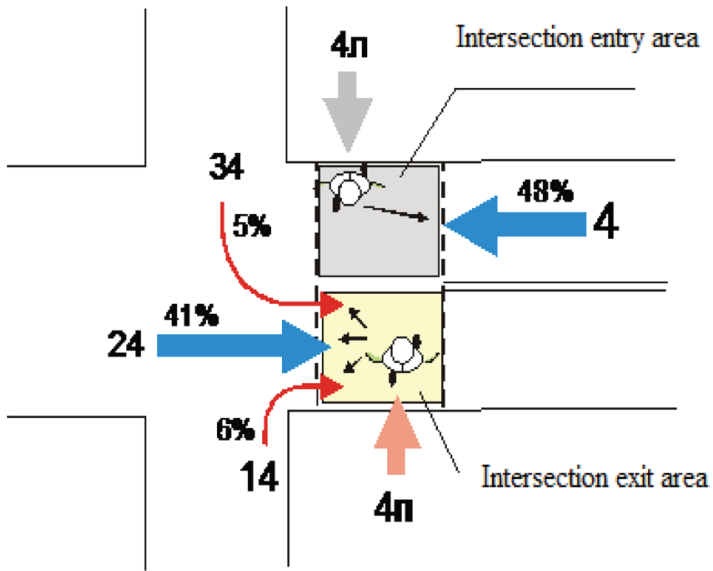

Fig. 3 Scheme of interaction of traffic and pedestrian flows at the crossing of a regulated intersection (figures in \% indicate the share of accidents)

when making decisions. It should be borne in mind that the desire to increase safety in a "turning vehicle-pedestrian" conflict by dividing flows over time with an increase in the number of traffic light phases often leads to an increase in the accident rate in general for a "transport-pedestrian" conflict for several reasons:

firstly, pedestrians wait longer for the green signal, which to a greater extent provokes them to violate the rules;

secondly, in some schemes of multiphase regulation, one half of the pedestrian crossing remains free from transport, but pedestrians are prohibited from crossing it, which also provokes them to violate the rules;

finally, thirdly, in a multiphase control, turning traffic flows usually occur due to the green signal of an additional traffic light section, which for many drivers, especially those in left-hand traffic, is associated with conflict-free traffic, so they perceive any pedestrians as violators with all the ensuing consequences.

Fig. 3 shows data on the distribution of accidents during the interaction of traffic and pedestrian flows at a pedestrian crossing located in the zone of a regulated intersection. Pedestrian crossings are assigned indices 1,2, 3 and 4 in accordance with the number of entrances. The pedestrian flow index consists of a crossing number and a letter indicating the direction of movement of the pedestrians (4П and 4Л in Fig. 3). At each of the crossings, two parts are distin-

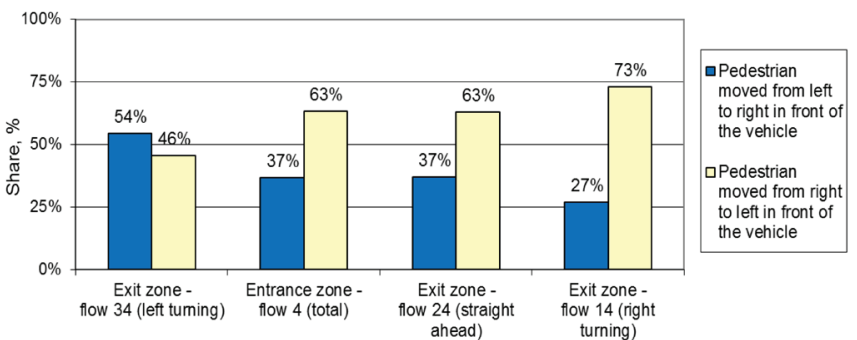

Fig. 4 Distribution of accidents involving pedestrians at traffic light intersections, depending on the direction of the pedestrian's movement

guished: the entrance zone, located on the lanes of the carriageway, along which vehicles approach the intersection and the exit zone located on the lanes of the carriageway along which vehicles leave the intersection.

Fig. 4 and Tab. 4 show the distribution of accidents at the pedestrian crossings of a traffic light intersection, depending on the direction of the traffic and pedestrian flows, which was obtained from an analysis of 1842 accidents in cities of the Republic of Belarus, including 194 accidents in "turning vehicle - pedestrian" conflicts.

The most dangerous collisions at crossroads are conflicts with direct-flow traffic flows (24 and 4), which are explained by the high speed of these flows. Such conflicts account for $89 \%$ of all accidents with pedestrians at traffic light intersections. Conflicts with left-turning drivers - pedestrians and right-turning drivers - pedestrian are approximately equivalent - they account for $5 \%$ and $6 \%$, respectively. The total accident rate in the exit zone from an intersection is slightly higher, which, among other things, is explained by the worse conditions of orientation for a pedestrian interacting with three multidirectional traffic flows.

In conflicts with direct transport, approximately two-thirds of accidents occur with the participation of pedestrians who have not yet reached the middle of the carriageway (conflicts 4-4l and 24-4p in Fig. 3). The main reason for this distribution (Tab. 4, Fig. 4) is the lack of time for the driver to respond, because the pedestrian is in the danger zone immediately after entering the roadway.

As a concomitant reason, approximately $20-25 \%$ of pedestrian conflicts with direct transport vehicles due to the insufficient length of the transition interval of traffic lights should be noted; the interval does not provide an opportunity for all pedestrians to clear the carriageway before the start of the movement of the conflicting traffic flow.

Tab. 4 Distribution of pedestrian arrivals at regulated intersections in cities of Belarus

\begin{tabular}{|c|c|c|c|c|c|c|c|}
\hline \multirow[b]{2}{*}{ Transition zone } & \multirow[b]{2}{*}{$\begin{array}{l}\text { Traffic flow } \\
\text { designation } \\
\text { (Fig.3) }\end{array}$} & \multirow[b]{2}{*}{ 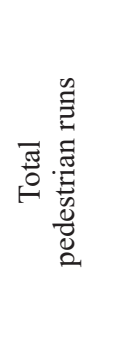 } & \multicolumn{2}{|c|}{ including: } & \multirow[b]{2}{*}{ 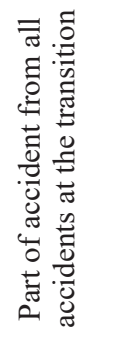 } & \multicolumn{2}{|c|}{ Accident rate } \\
\hline & & & 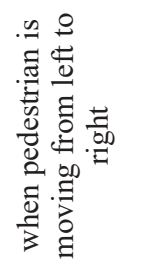 & 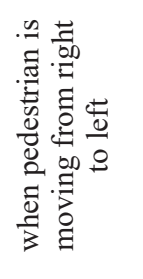 & & 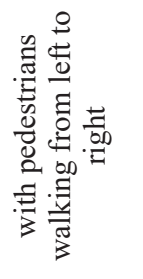 & 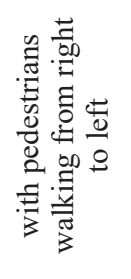 \\
\hline at the entrance & 4 (total) & 889 & 326 & 563 & $48.3 \%$ & $36.7 \%$ & $63.3 \%$ \\
\hline at the exit & 24 (transit) & 759 & 281 & 478 & $41.2 \%$ & $37.0 \%$ & $63.0 \%$ \\
\hline at the exit & 34 (left-turning) & 90 & 49 & 41 & $4.9 \%$ & $54.4 \%$ & $45.6 \%$ \\
\hline at the exit & 14 (right-turning) & 104 & 28 & 76 & $5.6 \%$ & $26.9 \%$ & $73.1 \%$ \\
\hline Total: & & 1842 & 684 & 1158 & $100 \%$ & $37.1 \%$ & $62.9 \%$ \\
\hline
\end{tabular}


In a right-hand traffic - pedestrian conflict, an additional reason complicating the conditions of interactions is the deterioration of lateral visibility for a pedestrian to whom the vehicle approaches from the rear to the left (conflict 14-4p in Fig. 3). As a result, the share of accidents involving pedestrians of the $4 \mathrm{p}$ flow ("associated path") for the right-hand flow reaches almost $75 \%$. In a conflict with left-hand traffic, a pedestrian moving in the 4-1 direction (conflict 34-4 1 in Fig. 3) cannot see the vehicle as well as pedestrians in the opposite direction. However, before entering the danger zone, a pedestrian in the $4 \mathrm{~L}$ direction moves for several seconds along the transition and, at this time, he is already in the driver's field of vision. As a result, the share of accidents for the left-hand flow involving pedestrians in both directions is almost the same. In general, with "passing" trajectories (conflicts $14-4 \mathrm{p}$ and $34-41$ ), 64\% of all accidents in a conflict were recorded as turning vehicles - pedestrians, which was taken into account when developing accident forecasting methods. If the driver, in a conflict with a pedestrian, gave way ahead of him in advance, or if the pedestrian intentionally refused to go first, then such a traffic situation qualified as potentially dangerous. If the driver or the pedestrian is forced to take urgent evasive actions, such a traffic situation qualifies as a conflict.

According to the degree of danger, there are light, medium and heavy traffic situations. In relation to the conflicts under study, the following classifications have been adopted:

light - the driver did not give way to the pedestrian, thereby forcing him to stop or accelerate sharply at the last moment (1-0.5 s), or the car stopped abruptly in front of the pedestrian (very dangerous);

medium - the driver did not give way to the pedestrian, forcing him to jump sharply from the conflict point at the very last moment (less than $0.5 \mathrm{~s}$ ), or the car stopped abruptly at the very last moment before the pedestrian was already at the conflict point (miraculously passed);

heavy - the driver did not give way to the pedestrian, as a result of which the car came into contact with the pedestrian, but did not cause any bodily harm (miraculously survived).

Collisions are also divided into light, medium and heavy:

As a result of a light collision, there is no significant damage to vehicles, goods or the arrangement of roads or bodily injuries to pedestrians. Many researchers combine light collisions and heavy traffic situations in one transition group.

Medium collisions lead to significant damage to vehicles, goods and roads, or to minor bodily injuries in people, but which do not lead to impaired health.

Heavy collisions are accompanied by injuries, injuries or death Such collisions qualify as accidents with victims and are divided into 2 groups: accidents with injuries and fatal accidents.

Since the accident rate of "the turning vehicle - pedestrian" conflict at traffic light intersections is low, it is hard to obtain a repre-

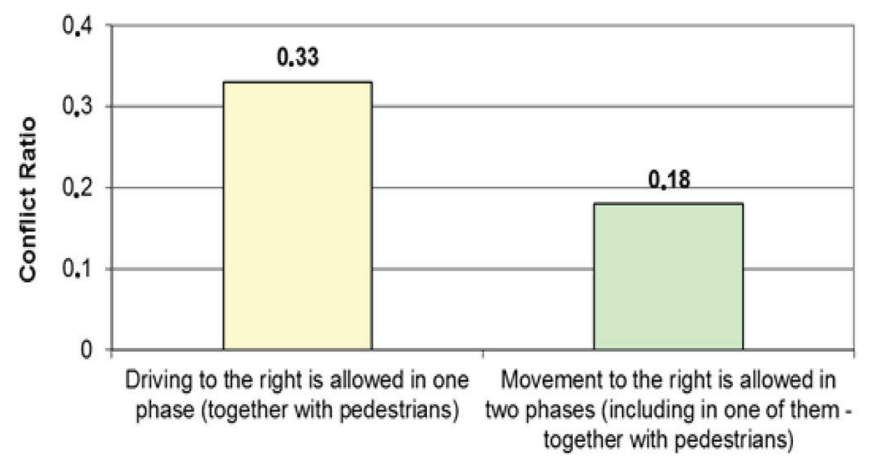

Fig. 5 The influence of the traffic control scheme of right-turn traffic flows on the Conflict Ratio $\eta_{\kappa}$ sentative sample of accidents. Therefore, studies were conducted by visual observations of traffic situations, including video recordings.

The studies were conducted for a total of 183 hours at 131 pedestrian crossings in Minsk and 26 pedestrian crossings in Grodno. The conditions of the traffic conflicts were recorded for 16,047 right-turning vehicles and 1651 left-turning vehicles. Of the 17,698 traffic situations, 2314 were classified as potentially dangerous, and 1160 were classified as traffic situations of which 1142 were classified as light, 16 as medium and 2 as severe.

To assess the conditions of conflict interactions between pedestrians and turning traffic flows, two indicators were introduced, i.e., the conflict ratio and the violations rate.

The conflict ratio is defined as the proportion of turning vehicles that come into conflicts with pedestrians:

$$
\eta_{\kappa}=\frac{n_{\kappa}}{n} \leq 1
$$

where

$n_{\kappa}-$ the number of vehicles conflicting with pedestrians,

$n-$ the total number of turning vehicles.

The conflict ratio evaluates the quality of the traffic light control circuit (from the viewpoint of traffic safety). The smaller $n$, the control scheme is safer. If the surface level pedestrian crossing is absent, $n_{\kappa}=0$, the duration of the transitional intervals provides the opportunity to be released from the danger zone by pedestrians and vehicles.

The violation rate is defined as the proportion of vehicles whose drivers created the conflict situation (CS) in relation to the number of conflicting vehicles:

$$
\eta_{H}=\frac{n_{H}}{n_{\kappa}} \leq 1 \text { (4) }
$$

where

$\eta_{H}$ - the number of vehicles creating a CS.

The violation rate characterizes the probability of CS in a "turning vehicle - pedestrian" conflict (the probability of a potentially dangerous situation developing into a conflict). The smaller $\eta_{H}$ the fewer violations and the conflict is safer. In the ideal case, $\eta_{H} \rightarrow 0$. However, $\eta_{H}>0$ is found most commonly in practice, because each driver has his own psychological factors. The main results of the experimental studies are shown in Tab. 5.

The results of the experimental studies make it possible to establish the dependencies of the conflict ratio and the violations rate on some parameters of the road that were used in the calculation model for predicting accidents and in assessing "turning vehicles - pedestrians" conflict control.

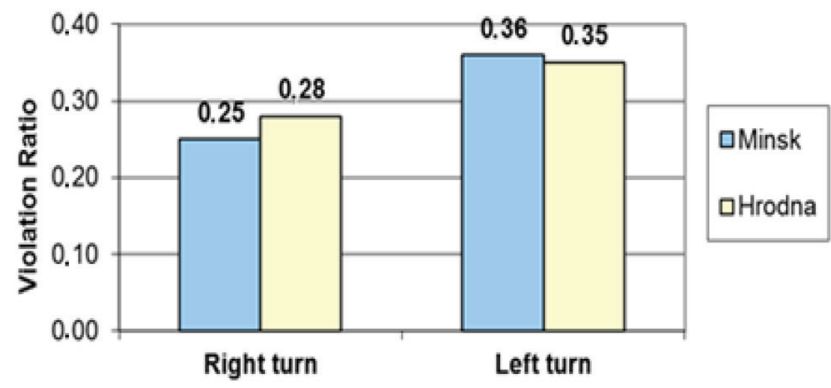

Fig. 6 Dependence of the Violation Ratio $\eta_{H}$ on the direction of movement of the turning vehicle 
Table 5 The results of the study of "pedestrian- turning transport" conflict situations

\begin{tabular}{|c|c|c|c|c|c|c|c|}
\hline \multirow[b]{2}{*}{ 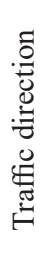 } & \multirow[b]{2}{*}{ Town } & \multirow[b]{2}{*}{ Driving conditions } & \multicolumn{3}{|c|}{ Number of vehicles } & \multicolumn{2}{|c|}{ Factor of } \\
\hline & & & Total & 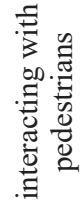 & 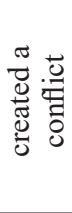 & 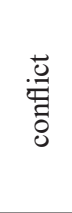 & $\frac{\stackrel{0}{0}}{\stackrel{0}{0}}$ \\
\hline \multirow{12}{*}{ 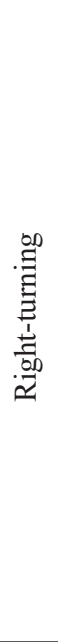 } & \multirow{6}{*}{ Minsk } & Total: & 13,372 & 3280 & 832 & 0.25 & 0.25 \\
\hline & & Including when driving on a signal: & & & & & \\
\hline & & of the main traffic light & 5912 & 1901 & 533 & 0,32 & 0,28 \\
\hline & & the additional section "to the right" & 440 & 94 & 34 & 0.21 & 0.36 \\
\hline & & the additional section "to the right" + information section & 3879 & 713 & 157 & 0.18 & 0.22 \\
\hline & & the additional section "to the right" + information plate & 3141 & 572 & 108 & 0.18 & 0.19 \\
\hline & \multirow{5}{*}{ Hrodna } & total: & 2675 & 432 & 121 & 0.16 & 0.28 \\
\hline & & Including when driving on a signal: & & & & & \\
\hline & & of the main traffic light & 228 & 98 & 21 & 0.43 & 0.21 \\
\hline & & the additional section "to the right" & 543 & 83 & 34 & 0.15 & 0.41 \\
\hline & & the additional section "to the right" + information section & 1904 & 251 & 66 & 0.13 & 0.26 \\
\hline & & Total for 2 cities: & 16,047 & 3712 & 953 & 0.23 & 0.26 \\
\hline \multirow{8}{*}{ } & \multirow{3}{*}{ Minsk } & total: & 1546 & 538 & 192 & 0.35 & 0.36 \\
\hline & & Including when driving on a signal: & & & & & \\
\hline & & of the main traffic light & 1546 & 538 & 192 & 0.35 & 0.36 \\
\hline & \multirow{4}{*}{ Hrodna } & total: & 105 & 43 & 15 & 0.41 & 0.35 \\
\hline & & Including when driving on a signal: & & & & & \\
\hline & & of the main traffic light & 82 & 31 & 6 & 0.38 & 0.19 \\
\hline & & the additional section "to the left" & 23 & 12 & 9 & 0.52 & 0.75 \\
\hline & & Total for 2 cities: & 1651 & 581 & 207 & 0.35 & 0.36 \\
\hline
\end{tabular}

The effect of the traffic light control scheme on the conflict ratio is shown in Fig. 5. It can be seen that the movement of the turning flow is allowed in two phases of the traffic light, but the movement of the pedestrian in only one of them. It significantly reduces the conflict ratio because part of the turning vehicles pass the crossing during the traffic light cycle when pedestrians are not allowed to cross.

Another factor that has an effect on the conflict ratio $\eta_{\kappa}$ is the rate of the crosswalk flow; if the rate of the crosswalk flow decreases, the conflict ratio $\eta_{\kappa}$ also decreases. When the crossing or pedestrian is absent, $\eta_{\kappa}=0$.

Fig. 6 shows the dependence of the violation rate on the direction of the turning movement.

In the left-hand flow, the share of drivers creating conflict situations is $30-40 \%$ higher than in the right-hand flow. This is due to the higher speed of the left-turn flow and the more difficult conditions for its implementation.

Fig. 7 shows the dependence $\eta_{H}$ of the traffic flow's composition. The amount of drivers creating conflict situations increases with an increase in the reduction coefficient. That is explained by the difference in the characteristics of the vehicle and pedestrian, complications of the braking maneuver for a large-sized vehicle, and also deterioration of the lateral visibility conditions (especially to the right) from the cab of a truck, bus or trolleybus.

The dependence of the $\eta_{H}$ on the size of a group of pedestrians in front of a vehicle is shown in Fig. 8. The most dangerous is the crossing of the roadway alone. With an increase in the number of pedestrians in the group, the proportion of drivers violating the rules decreases, which is explained by the more confident behavior of pedestrians in the group, a decrease in the possibility of getting around the group by a vehicle, and an increase in the risk for the driver to hit a pedestrian. Fig. 9.

The dependence of the $\eta_{H}$ on the regulation method is shown in

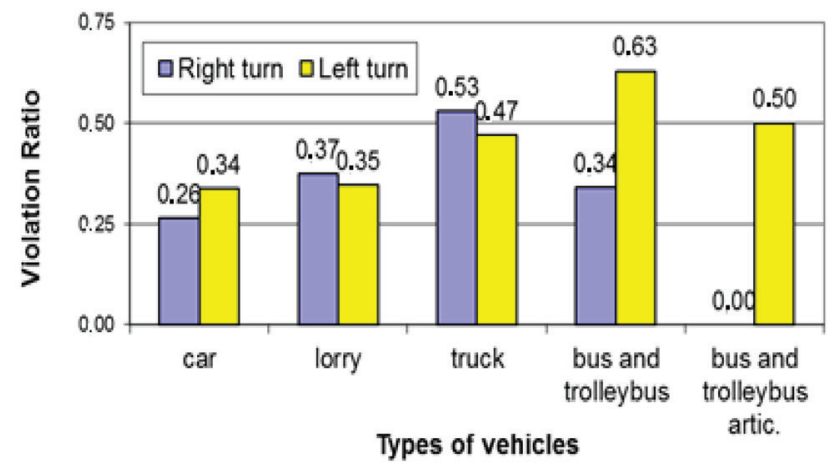

Fig. 7 The dependence of Violation Ratio $\eta_{H}$ on the composition of the turning vehicle flow (data for Minsk) 


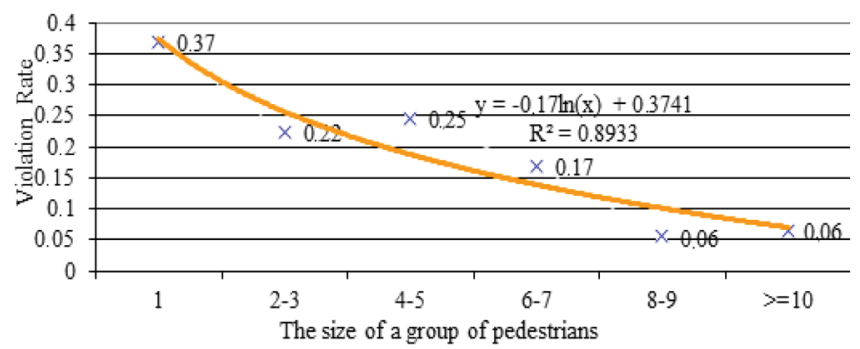

Fig. 8 The dependence of the Violations Ratio $\eta_{H}$ on the size of the group of pedestrians in front of a vehicle

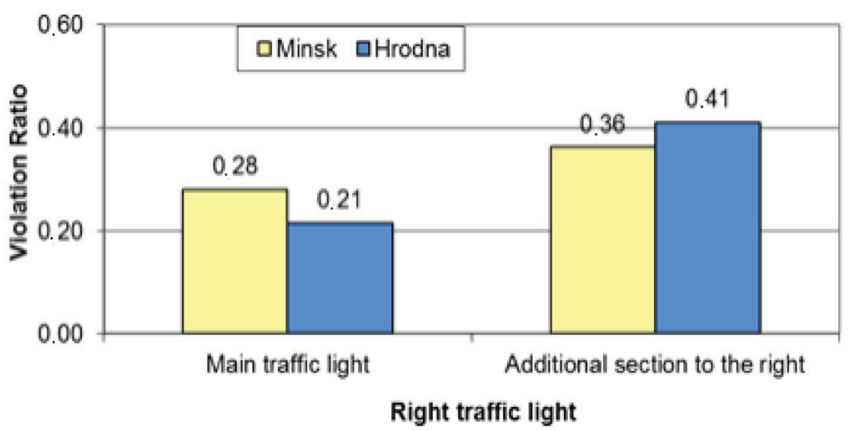

Fig. 9The dependence of the Violation Ratio $\eta_{H}$ on the type of traffic signal that regulates the movement to the right

When moving to the right according to the signal of the additional traffic light, the value $\eta_{H}$ increases by more than $35 \%$ compared with the movement of the signal of the main traffic light, which is explained by the peculiarities of the perception by drivers of the signals of the additional sections.

\section{CONCLUSIONS}

As a result of the analysis, the main indicators and features of the accident rate during the joint movement of pedestrians and turning traffic flows at traffic light intersections have been determined. It was found that in general, accidents in the conflict under study are small and account for $5-20 \%$ of the accidents at traffic light intersections with pedestrians. Nevertheless, accidents during the joint movement of pedestrians and turning traffic flows exist and must be taken into account when making decisions on the organization of traffic.

The experimental studies of conflict situations in the interactions of pedestrians and turning traffic flows at traffic light intersections allowed for the development of an improved methodology for predicting accidents. At the same time, the reduction of conflict situations by the degree of danger and the dynamics (by conflict situations), and the reduction of accidents by the severity of the consequences were used firstly in the calculation forecasting model. This allowed foe an increase in the accuracy of the forecast by several times in comparison with known methods.

The most dangerous situations at crossroads is a conflict with traffic flows in straight directions. Such conflicts account for $89 \%$ of all accidents with pedestrians at traffic light intersections. "Pedestrian - left-turning transport" and "pedestrian - right-turning transport" conflicts are approximately equivalent; they account for $5 \%$ and $6 \%$ of accidents, respectively. The total accident rate in the exit zone from an intersection is slightly higher, which, among other things, is explained by the worse orientation conditions for a pedestrian interacting with three multidirectional traffic streams.
The share of drivers creating conflict situations in a left-turning flow is $30-40 \%$ more than in a right-turning flow. This fact is explained by the higher speed of the left-turning flow and the more difficult conditions for its performance.

The studies presented cover a wide range of issues related to changing the functional state of the driver from the factors of the road environment. The presented approach for determining the parameters of conflict situations can be further used to evaluate traffic conditions on routes. The presented dependencies of the changes of the functional state of the driver on changes in illumination showed that at low levels of illumination, there is an increase in the number of accidents and their severity. Under stress, drivers can increase the level of accidents. Drivers' behavior in different driving conditions requires further investigation and assessments of their impact on conflicts and traffic violations. 


\section{REFERENCES}

Archer, J. (2001) Traffic conflict technique: Historical to current state-of-the-art. Stockholm, Sweden: Kungl Tekniska Högskolan. Institutionen för Infrastruktur KTH, Stockholm, 2001. Access at: http://www.ctr.kth.se/publications/ctr2001_05.pdf.

Avineri, E. - Shinar, D. - Susilo, Y. O. (2012) Pedestrians'behaviour in cross walks: the effects of fear of falling and age. Accident Analysis \& Prevention, 44(1), 30-34.

Azemsha S.A. - Galushko V.N. - Skirkovski S.V. - Vrubel Y.A. (2015) Data analysis of traffic accidents and their causes in Gomel for 2013 and 2014, Science \& Technique, 3, 65-73 (in Russian).

Breen, J. (2002) European priorities for pedestrian safety. In: Pedestrian Safety Seminar, Sydney, 19 pp. Access at: http://www. maa.nsw.gov.au/getfile.aspx?Type $=$ document $\& I D=44320 \& O b-$ jectType $=3 \&$ ObjectID $=3905 /$

Bulbenkov V.V. - Lyvanskyi O.H. - Poludnia E.E. (2011) Svedenyia o sostoianyy dorozhno-transportnoi avaryinosty $v$ Respublyke Belarus v 2010 hodu : analytycheskyi sb. / sost.:- Mynsk : MVD Resp. Belarus,. -89 pp.

Bulbenkov V.V. - Lyvanskyi O.H. - Melchenko N.A. (2012) Svedenyia o sostoianyy dorozhno-transportnoi avaryinosty $v$ Respublyke Belarus v 2011 hodu : analytycheskyi sb. Mynsk : Polyhrafycheskyi Tsentr MVD Resp. Belarus, 89 pp.

Draskóczy, M. - Hydén, C. (1995) Pedestrian safety measures-Past and future. Risser et al. (eds.), 86-96.

Földes, D. - Csiszár, C. (2016) Conception of future integrated smart mobility. In 2016 Smart Cities Symposium Prague (SCSP), Prague, (pp. 1-6). IEEE. DOI: 10.1109/SCSP.2016.7501022

Galkin A. - Drill N. - Bibik N. (2016) Applying City Marketing as a Tool to Support Sustainable Development in Small Cities: Case Study in Ukraine. Transportation Research Procedia, 16, 46-53

Galkin, A. - Davidich, N. - Melenchuk, T. - Kush, Y. - Davidich, Y., - Lobashov, O. (2018) Modelling Truck's Transportation Speed on the Route Considering Driver's State. Transportation research procedia, 30, 207-215.

Gorodokin, V. - Almetova, Z. - Shepelev, V. (2017) Algorithm of signalized crossroads passage within the range of permissive-to-restrictive signals exchange. Transportation Research Procedia, 20, 225-230.

Ekman, L. (1997) Fotgängares situation vid övergångsställe. Institutionen för trafikteknik, LTH. tekniska högskolan i lund, lunds universitet, $17 \mathrm{pp}$.

Ewing, R. (1996). Pedestrian and transit friendly design. Joint Center for Environment and Urban Problems. Florida Atlantic University/Florida International University, USA, 103 pp.

Kapski, D. (2008) Prognozirovanie avarijnosti $v$ dorozhnom dvizhenii. Minsk: BNTU, 243 pp.

Kapski, D. V. - Pegin, P. A. - Korchagin, V. A. (2015) The Features of Evaluation of Vehicle and Pedestrian Conflict at Intersections. Bulletin of PNU, 37(2).
Lenard, J. - Badea-Romero, A. - Danton, R. (2014) Typical pedestrian accident scenarios for the development of autonomous emergency braking test protocols. Accident Analysis \& Prevention, 73, 73-80.

Lord, D. - Smiley, A., - Haroun, A. (1998) Pedestrian accidents with left-turning traffic at signalized intersections: Characteristics, human factors, and unconsidered issues. In 77th Annual Transportation Research Board Meeting, Washington, DC, USA. Access at: http://safety.fhwa.dot.gov/ped_bike/docs/00674.pdf.

National Highway Traffic Safety Administration (2004) Traffic Safety Facts, 2004 Data: Motorcycles. Washington, DC: National Highway Traffic Safety Administration, US Deprt. of Transport, DOT HS, 810, 620.

Prasolenko, O. - Burko, D. - Tolmachov, I. - Gyulyev, N. - Galkin, A. - Lobashov, O. (2019) Creating safer routing for urban freight transportation. Transportation research procedia, 39, 417-427.

Schlosser, T. - Schlosser, P. - Cápayová, S. - Hodáková, D. (2017) Terminals for Suburb Bus Transport in Bratislava. In IOP Conference Series: Materials Science and Engineering (Vol. 245, No. 4, p. 042059). IOP Publishing. Available at: doi:10.1088/1757$899 X / 245 / 4 / 042059$

Schlosser, T. - Zuzulová, A. - Cápayová S. - Schlosser, P. (2016) New public transport tramway line in Bratislava - Way of improving the environmental conditions, In SGEM 2016. 16th Internation-al Multidisciplinary Scientific GeoConference. Book 4. Energy and Clean Technologies: conference proceedings. Albena, Bulgaria, 30 June - 6 July 2016. 1. ed. Sofia: STEF 92 Technology, 2016, pp. 475-482. ISSN 1314-2704. ISBN 978-619-7105-643, WOS:000391348700061.

Vakulenko, K.- Kuhtin, K.- Afanasieva, I. - Galkin, A. (2019) Designing Optimal Public Bus Route Networks in a Suburban Area. Transportation Research Procedia, 39, 554-564.

Vrubel, Yu. A. - Kapskyi, D. V.(2013) Opasnosty v dorozhnom dvyzhenyy. M.: Novoe znanye, $244 \mathrm{pp}$.

Vrubel, Yu. A. - Kapski, D. V. - Kot, E. N. (2006) Opredelenye poter $v$ dorozhnom dvyzhenyy. Mynsk: BNTU, 240 pp.

World Health Organization. Violence, Injury Prevention, \& World Health Organization. (2013) Global status report on road safety 2013: Supporting a decade of action. World Health Organization.

Zegeer, C. V. - Bushell, M. (2012) Pedestrian crash trends and potential countermeasures from around the world. Accident Analysis \& Prevention, 44(1), 3-11.

Zeedyk, M. S. - Kelly, L. (2003) Behavioural observations of adultchild pairs at pedestrian crossings. Accident Analysis and Prevention 35, 771-776. 